Research/Technical Note

\title{
Determination of Water Rate in Gas Oil and Fuel Oil by Extraction with Betacarotenes Molecules Using a Heavy Oil Clevenger Extractor, Process Validation by SPC
}

\author{
Andry Tahina Rabeharitsara, Phandry Nomena Ndjiva Rabearimihaja, \\ Nambinina Richard Randriana \\ Department Genie Chimique of E.S.P.A, Polytechnic University of Antananarivo, Antananarivo, Madagascar

\section{Email address:} \\ rabeharitsara_andrytahina@yahoo.fr(A. T. Rabeharitsara),phandryrandjiva@gmail.com (P. N. N. Rabearimihaja), \\ richardrandriana@yahoo.fr (N. R. Randriana) \\ ${ }^{*}$ Corresponding author
}

To cite this article:

Andry Tahina Rabeharitsara, Phandry Nomena Ndjiva Rabearimihaja, Nambinina Richard Randriana. Determination of Water Rate in Gas Oil and Fuel Oil by Extraction with Betacarotenes Molecules Using a Heavy Oil Clevenger Extractor, Process Validation by SPC. American Journal of Applied Chemistry. Vol. 4, No. 3, 2016, pp. 111-119. doi: 10.11648/j.ajac.20160403.17

Received: May 10, 2016; Accepted: May 23, 2016; Published: June 4, 2016

\begin{abstract}
Water rate in hydrocarbons such as gas oil and fuel oil was determined by extraction with betacarotenes molecules at temperature between $120^{\circ} \mathrm{C}$ and $140^{\circ} \mathrm{C}$ using a heavy oil Clevenger extractor. This extraction was investigated like a process and the water rate data of gas oil and fuel oil was exploited using Statistical Process Control tools. We noticed that for gas oil and fuel oil, data follow a normal distribution. That is to say, this hydrocarbons water rate determination process by extraction with betacarotenes molecules using a heavy oil Clevenger extractor is statistically in control. So, the outcomes of the process can be accurately predicted depending on the volume of gas oil or fuel oil to be characterized. According to the Gas oil and fuel oil Total service specification target with heavy oil Clevenger extractor tolerance and standard deviation this water rate determination process is apt and able to produce water rate results with quality six sigma. The water rate in Malagasy station imported gas oil $(800 \mathrm{ml})$ and fuel oil $(200 \mathrm{ml})$ are respectively $0.1476 \mathrm{ml}$ and $0.475 \mathrm{ml}$. We notice that after use the betacarotenes molecules are recycled.
\end{abstract}

Keywords: Betacarotene, Gas Oil, Fuel Oil, Water Rate, Extraction, Statistical Process Control SPC, Quality Sigma, Process, Process Aptitude $\mathrm{C}_{\mathrm{p}}$, Ratio Aptitude $\mathrm{C}_{\mathrm{pk}}$

\section{Introduction}

Nowadays, environmental protection must form integral part of any process [1]. For a few decades, the quality control laboratories of oil industries and oil companies have used a quantity considerable of benzene to determine and to control the water rate of their hydrocarbons $[2,3,4,5]$. It produces considerable consequences on the human health and the environment. The aim of this publication is to show a new process using a reagent environmentally responsible for determining the water rate in hydrocarbons such as gas oil and fuel oil. This new process is based on using the reagent betacarotenes molecules to extract the water molecules present in gas oil and fuel oil. The extraction temperature is between $120^{\circ} \mathrm{C}$ to $140^{\circ} \mathrm{C}$ and based on the formation of hydrogen bond links between betacarotenes molecules and water molecules. We noticed that apparently water molecules move on the betacarotenes molecules from the round-bottomed flask to the Clevenger extractor. For each water rate determination we use only $10 \mathrm{ml}$ of betacarotenes for $800 \mathrm{ml}$ of gas oil and $200 \mathrm{ml}$ of fuel oil and each extraction lasts approximately $35 \mathrm{mn}$ because of the effectiveness of the moving hydrogen bond links between the water molecules and the betacarotenes molecules. The water rate data of gas oil and fuel oil was exploited using Statistical Process Control tools [6] and show that this water determination process is apt to 
produce results with quality six sigma in comparison to Total service specification target. The equality of the process aptitude $\mathrm{Cp}$ and the ratio aptitude $\mathrm{Cpk}$ indicates that the middle values of the normal distribution data of water rate in $800 \mathrm{ml}$ of gas oil and $200 \mathrm{ml}$ fuel oil respectively $0.1476 \mathrm{ml}$ and $0.475 \mathrm{ml}$ are probably their water rate [7]. The recycling of betacarotenes molecules used in gas oil and fuel oil are investigated using the acetic acid solvent [8] and their recycle rates are respectively $75 \%$ and $60 \%$ with automatically the recycling of the hydrocarbons gas oil and fuel oil.

\section{Water Rate in Gas Oil and Fuel Oil Determined by Extraction with Betacarotenes Molecules Using a Heavy Oil Clevenger Extractor}

\subsection{Materials Used for This Water Rate Determination Process}

\subsubsection{Materials and Reagents}

To extract the water in gas oil and fuel oil we used betacarotenes molecules like active reagents, hexane solvent and an extraction assembly composed by:

- 1 liter round-bottomed flask for Gasoil water extraction and $250 \mathrm{ml}$ round-bottomed flask for fuel oil water extraction.

- Heavy oil Clevenger extractor.

- Condenser.

- Heating up round-bottomed flask.

\subsubsection{Figure of the Extraction Assembly}

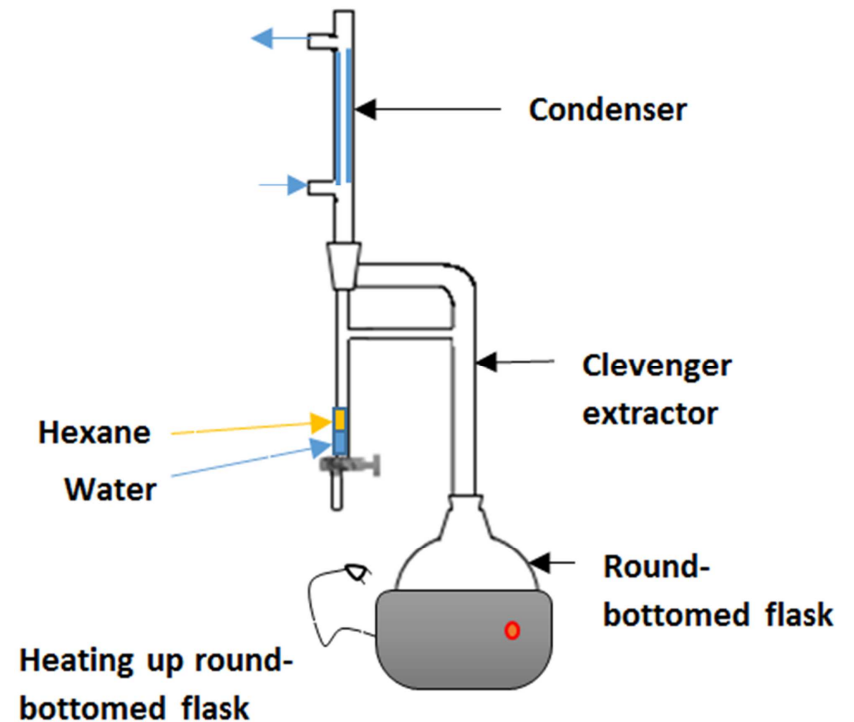

Figure 1. Water extraction with betacarotenes molecules using a heavy oil Clevenger extractor assembly.

\subsection{Water Extraction Procedures}

\subsubsection{Gas Oil Water Extraction Procedure}

We took 1 liter round-bottomed flask and put $800 \mathrm{ml}$ of gasoil with $10 \mathrm{ml}$ of betacarotenes actives molecules inside. We agitated it for a few seconds and put it in the heating up round-bottomed flask which is programmed to heat progressively from ambient temperature to $120^{\circ} \mathrm{C}$. We took the Clevenger apparatus and put a few milliliters of water then $1 \mathrm{ml}$ of hexane inside the graduated tube. We notice that the solvent is up together on top the water because of its density [9] is lower than the water density. Its role is not only to facilitate and to check the water increase value reading but also the hexane coolness activate the hot betacarotenes-water hydrogen bond transport to the graduation tube and guarantee its dissociation: betacarotenes molecules are retained by hexane solvent, the water molecules is gone underneath together. Then, we assemble the round-bottomed flask, the heavy oil Clevenger extractor and the condenser to constitute the assembly. Finally, we start to heat and after a few minutes the water extraction begin and its level in the Clevenger rise progressively to be stabilized after approximatively thirty five minutes. The water volume $\mathrm{X}$ corresponding to this augmentation is the water extracted in $800 \mathrm{ml}$ of gasoil. That is to say, the water rate in $800 \mathrm{ml}$ of gasoil is $\mathrm{X} \mathrm{ml}$.

\subsubsection{Fuel Oil Water Extraction Procedure}

We took $250 \mathrm{ml}$ round-bottomed flask and put $200 \mathrm{ml}$ of fuel oil with $10 \mathrm{ml}$ of betacarotenes actives molecules inside. We agitated it for a few seconds and put it in the heating up round-bottomed flask which is programmed to heat progressively from ambient temperature to $140^{\circ} \mathrm{C}$. We took the Clevenger apparatus and put a few milliliters of water then $1 \mathrm{ml}$ of hexane inside the graduated tube. We notice that the solvent is up together on top the water because of its density [9] is lower than the water density. Its role is not only to facilitate and to check the water increase value reading but also the hexane coolness activate the hot betacarotenes-water hydrogen bond transport to the graduation tube and guarantee its dissociation: betacarotenes molecules are retained by hexane solvent, the water molecules is gone underneath together. Then, we assemble the round-bottomed flask, the heavy oil Clevenger extractor and the condenser to constitute the assembly. Finally, we start to heat and after a few minutes the water extraction begin and its level in the Clevenger rise progressively to be stabilized after approximatively thirty five minutes. The water volume $\mathrm{X}$ corresponding to this augmentation is the water extracted in $200 \mathrm{ml}$ of fuel oil. That is to say, the water rate in $200 \mathrm{ml}$ of fuel oil is X ml.

\section{Principle and Mechanism of Water Extraction in Gas Oil and Fuel Oil by Betacarotenes Molecules}

\subsection{Principle of Hydrogen Bond Link Between Betacarotenes Molecules and Water}

It was shown that hydrogen bond link [10] exist between betacarotenes molecules and animal's grease or betacarotenes molecules and vegetable's grease. The hydrogen bond is an attractive interaction between a 
hydrogen atom from a molecule or a molecular fragment $\mathrm{X}$ $\mathrm{H}$ in which $\mathrm{X}$ is more electronegative than $\mathrm{H}$, and an atom or a group of atoms in the same or a different molecule, in which there is evidence of bond formation. A typical hydrogen bond may be depicted as $\mathrm{X}-\mathrm{H} \ldots \mathrm{Y}-\mathrm{Z}$, where the three dots denote the bond. $\mathrm{X}-\mathrm{H}$ represents the hydrogen bond donor. The acceptor may be an atom or an anion $\mathrm{Y}$, or a fragment or a molecule $\mathrm{Y}-\mathrm{Z}$, where $\mathrm{Y}$ is bonded to $\mathrm{Z}$. In some cases, $\mathrm{X}$ and $\mathrm{Y}$ are the same. In more specific cases, $\mathrm{X}$ and $\mathrm{Y}$ are the same and $\mathrm{X}-\mathrm{H}$ and $\mathrm{Y}-\mathrm{H}$ distances are the same as well leading to symmetric hydrogen bonds. In any event, the acceptor is an electron rich region such as, but not limited to, a lone pair of $Y$ or $\pi$-bonded pair of Y-Z. [10]. So, in this water extraction process in gas oil and fuel oil by betacarotenes molecules, water molecules $\mathrm{H}_{2} \mathrm{O}$ are the molecular fragment $\mathrm{O}-\mathrm{H}$ which have hydrogen bond with the acceptor $\pi$-bonded pair, electron rich regions of betacarotenes molecules.

\subsection{Mechanism of Water Extraction by Betacarotenes Molecules}

The goal of this extraction process is to create this hydrogen bond links between betacarotenes molecules and water molecules in gas oil and fuel oil by heating progressively the solution from ambient temperature to $120^{\circ} \mathrm{C}$ for gas oil solution and to $140^{\circ} \mathrm{C}$ for fuel oil solution [figure 2]. Once created, the coolness of hexane solvent not only activate the transport of the hot betacarotenes-water hydrogen bond to the graduation tube but also guarantee its dissociation such as betacarotenes molecules are retained by hexane solvent and the water molecules is gone underneath together. The level of the water underneath and the hexane solvent on top rise together and give the hydrocarbons water volume extracted.

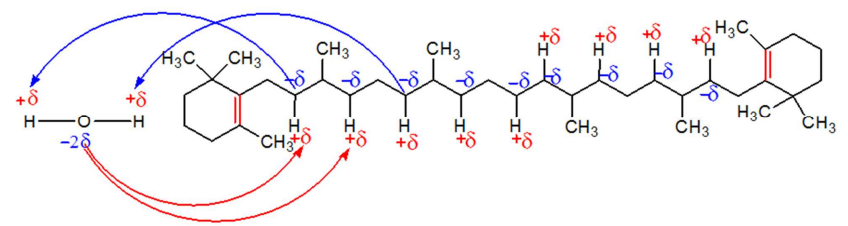

Figure 2. Figure of hydrogen bond links between a betacarotene molecule and water molecules.

\section{Results of Water Rate Extraction with Betacarotene Molecules Using a Heavy oil Clevenger Extractor Process}

\subsection{Results of Water Rate in Gas Oil}

Gas oil was taken in five different Malagasy hydrocarbons stations. So, five sampling were carried out. For each sample we took four times $800 \mathrm{ml}$ of gasoil. Finally, for each volume we extracted with betacarotenes molecules the water inside using the procedure described previously $(\$ 2.3 .1)$. We obtain in the table 1 four observations for each station corresponding to the water rate extracted in $800 \mathrm{ml}$ gasoline.
Table 1. Water rate extracted with betacarotene molecules in $800 \mathrm{ml}$ volume $\mathrm{V}$ of gasoline using a Clevenger extractor process.

\begin{tabular}{lllll}
\hline $\begin{array}{l}\text { SAMPLING } \\
\text { [Station }\end{array}$ & \multicolumn{4}{l}{$\begin{array}{l}\text { Water rate }[\mathbf{m l}] \text { extracted with betacarotene molecules } \\
\text { in } 800 \\
\text { ml volume } \mathbf{V} \text { of gasoline using a Heavy oil } \\
\text { Clevenger extractor process }\end{array}$} \\
\cline { 2 - 5 } & $\mathbf{V}$ & $\mathbf{V}$ & $\mathbf{V}$ & $\mathbf{V}$ \\
\hline Station 1 & 0,150 & 0,140 & 0,155 & 0,145 \\
Station 2 & 0,145 & 0,135 & 0,150 & 0,155 \\
Station 3 & 0,140 & 0,150 & 0,145 & 0,150 \\
Station 4 & 0,160 & 0,160 & 0,150 & 0,140 \\
Station 5 & 0,155 & 0,145 & 0,140 & 0,150 \\
\hline
\end{tabular}

\subsection{Results of Water Rate in Fuel Oil}

Fuel oil isn't used as domestic hydrocarbons in Madagascar. So, there is no large distribution of this oil. Only a few companies used it to be a generator fuel. In this case, we have taken 15 liter of fuel oil. At different moments, five sampling were carried out. For each sample we took four times $200 \mathrm{ml}$ of fuel oil. Finally, for each volume we extracted with betacarotenes molecules the water inside using the procedure described previously $(\$ 2.3 .2)$. We obtain in the table 2 four observations for each sample corresponding to the water rate extracted in $200 \mathrm{ml}$ fuel oil.

Table 2. Water rate extracted with betacarotene molecules in $200 \mathrm{ml}$ volume $\mathrm{V}$ of fuel oil using a Clevenger extractor process.

\begin{tabular}{lllll}
\hline \multirow{2}{*}{$\begin{array}{l}\text { SAMPLING } \\
\text { [Sample }\end{array}$ ] } & \multicolumn{4}{l}{$\begin{array}{l}\text { Water rate }[\mathbf{m l} \text { extracted with betacarotene } \\
\text { molecules in } \mathbf{2 0 0} \mathbf{~ m l} \text { volume } \mathbf{V} \text { of fuel oil using a Heavy } \\
\text { oil Clevenger extractor process }\end{array}$} \\
\cline { 2 - 5 } & $\mathbf{V}$ & $\mathbf{V}$ & $\mathbf{V}$ & $\mathbf{V}$ \\
\hline Sample 1 & 0,5 & 0,6 & 0,4 & 0,5 \\
Sample 2 & 0,3 & 0,4 & 0,6 & 0,5 \\
Sample 3 & 0,4 & 0,6 & 0,5 & 0,4 \\
Sample 4 & 0,5 & 0,4 & 0,5 & 0,6 \\
Sample 5 & 0,4 & 0,5 & 0,6 & 0,4 \\
\hline
\end{tabular}

\section{Statistical Control and Aptitude of Water Extraction in Gas Oil and Fuel Oil by Betacarotenes Molecules Process}

\subsection{Statistical Process Control (SPC) Tools Used for Controlling This Water Rate Determination by Its Extraction in Gas Oil And Fuel Oil by Betacarotenes Molecules Using a Heavy Oil Clevenger Extractor Process}

Variation is present in any process, deciding when the variation is natural and when it needs correction is the key to quality control. Statistical Process Control is an analytical decision making tool which allows us to see when a process statistically in control is working correctly and when it is not. The foundation for Statistical Process Control was laid by Dr. Walter Shewart working in the Bell Telephone Laboratories in the 1920 s conducting research on methods to improve quality and lower costs. He developed the concept of control with regard to variation, and came up with Statistical Process Control Charts which provide a simple way to determine if the 
process is in control or not [6]. For over 50 years clinical laboratories have embraced Shewhart's ideas and incorporated statistical process control into standard operating procedures for clinical laboratory quality control [11-12-13] and proficiency testing [14]. So, the statistical control of the processes is a tool for data analysis. It consists in applying statistical techniques to determine if the outgoing ones of a process are in conformity with their specifications. Statistical Process Control is an analytical decision making tool which allows you to see when a process is working correctly and when it is not. As regards Statistical Process Control, one exploits primarily diagrams and charts. There are two types of charts used on Statistical Process Control, once there are bell-curve like histogram or normal probability plot charts which confirm if the process is statistically in control or not and second there are control charts such as Range $\mathrm{R}$-chart and $\mathrm{x}$-bar graphics [6].

\subsubsection{Bell-Curve: Normal Probability Plot and Histogram of This Water Rate Determination Process Used in Gas Oil and Fuel Oil}

For each sampling the water rate extracted on gasoline and fuel oil are between the neighboring of the medium value (x-bar) minus standard deviation $(\delta)$ and the medium value plus standard deviation [Table 3 - Table 4]. That is to say, the dispersion of these water rate extracted are stable along the time either in gas oil either in fuel oil. It confirms that water rate determination by its extraction with betacarotenes molecules using a heavy oil Clevenger extractor process is statistically in control.

Table 3. $\bar{x}$ and $\delta$ values of water rate data in $800 \mathrm{ml}$ of gas oil determinated by its extraction with betacarotenes molecules using a heavy oil Clevenger extractor process.

\begin{tabular}{|c|c|c|c|c|c|c|c|c|}
\hline \multirow{2}{*}{$\begin{array}{l}\text { SAMPLING } \\
\text { [Station } \\
\text { [S }\end{array}$} & \multicolumn{8}{|c|}{$\begin{array}{l}\text { water rate }[\mathrm{ml}] \text { in } 800 \mathrm{ml} \text { of gas oil determinated by its extraction with betacarotenes molecules using a heavy oil Clevenger } \\
\text { extractor process }-\overline{\mathrm{x}} \text { and } \delta \text { values }\end{array}$} \\
\hline & $\mathbf{V}$ & $\mathbf{V}$ & $\mathbf{V}$ & V & $\bar{x}$ & $\delta$ & $\bar{x}-\delta$ & $\bar{x}+\delta$ \\
\hline Station 1 & 0,150 & 0,140 & 0,155 & 0,145 & 0,147 & 0,006 & 0,141 & 0,153 \\
\hline Station 2 & 0,145 & 0,135 & 0,150 & 0,155 & 0,146 & 0,009 & 0,137 & 0,155 \\
\hline Station 3 & 0,140 & 0,150 & 0,145 & 0,150 & 0,146 & 0,005 & 0,141 & 0,151 \\
\hline Station 4 & 0,160 & 0,160 & 0,150 & 0,140 & 0,152 & 0,010 & 0,142 & 0,162 \\
\hline
\end{tabular}

Table 4. $\bar{x}$ and $\delta$ values of water rate data in $200 \mathrm{ml}$ of fuel oil determinated by its extraction with betacarotenes molecules using a heavy oil Clevenger extractor process.

\begin{tabular}{|c|c|c|c|c|c|c|c|c|}
\hline \multirow{2}{*}{$\begin{array}{l}\text { SAMPLING } \\
\text { [Sample } \\
\text { [ ] }\end{array}$} & \multicolumn{8}{|c|}{$\begin{array}{l}\text { water rate }[\mathrm{ml}] \text { in } 200 \mathrm{ml} \text { of fuel oil determinated by its extraction with betacarotenes molecules using a heavy oil Clevenger } \\
\text { extractor process }-\overline{\mathbf{x}} \text { and } \delta \text { values }\end{array}$} \\
\hline & $\mathbf{V}$ & $\mathbf{V}$ & $\mathbf{V}$ & $\mathbf{V}$ & $\overline{\bar{x}}$ & $\delta$ & $\bar{x}-\delta$ & $\bar{x}+\delta$ \\
\hline Sample 1 & 0,5 & 0,6 & 0,4 & 0,5 & 0,147 & 0,006 & 0,141 & 0,153 \\
\hline Sample 2 & 0,3 & 0,4 & 0,6 & 0,5 & 0,146 & 0,009 & 0,137 & 0,155 \\
\hline Sample 3 & 0,4 & 0,6 & 0,5 & 0,4 & 0,146 & 0,005 & 0,141 & 0,151 \\
\hline Sample 4 & 0,5 & 0,4 & 0,5 & 0,6 & 0,152 & 0,010 & 0,142 & 0,162 \\
\hline
\end{tabular}

If we trace the figures of normal probability plot [figure 3.a - figure 3.b] which are the z-value according to the sorted data, we obtain points which are roughly in a straight line either with gas oil either with fuel oil. It indicates that the data of the water rate determinated by its extraction with betacarotenes molecules using a heavy oil Clevenger extractor process have a normal distribution [15], in other words they are statistically in control [6]. This affirmation is confirmed by the histogram of the data [figure 4.a - figure 4.b] which are a bell-curve.
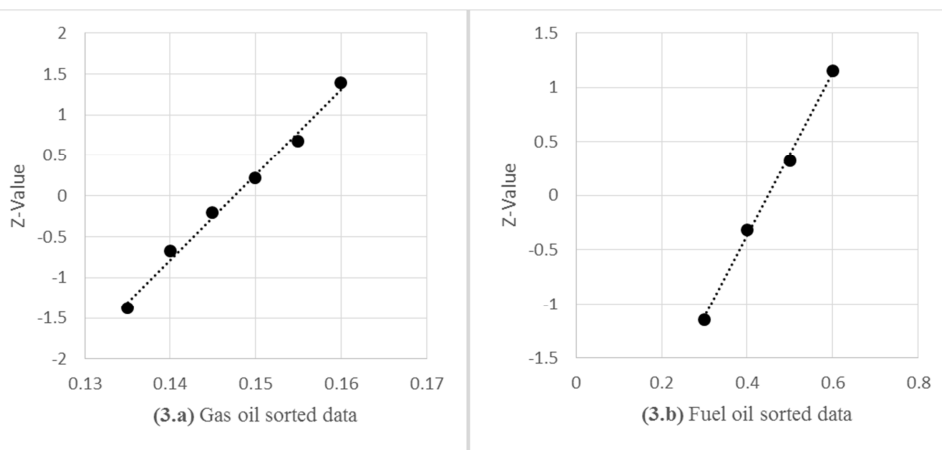

Figure 3. Normal probability plot of the water rate determinated by extraction with betacarotenes molecules using a heavy oil Clevenger extractor process for gas oil data (3.a) and for fuel oil data (3.b). 


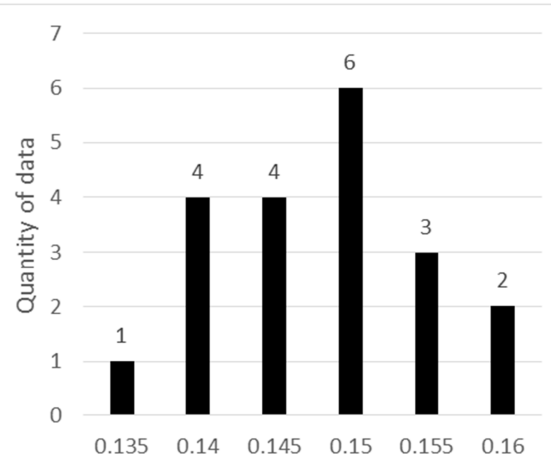

(4.a) Gas oil sorted data

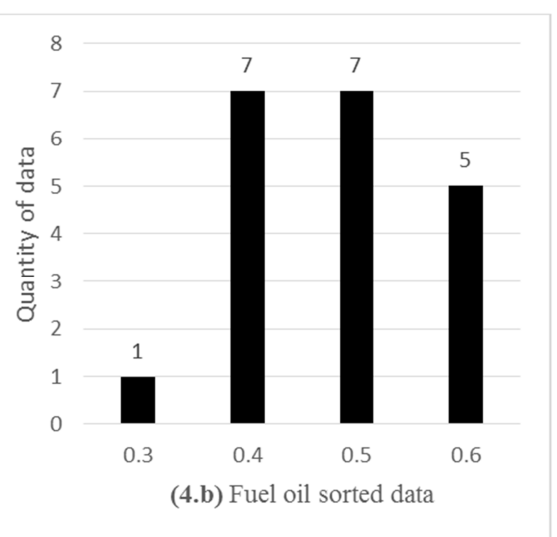

(4.b) Fuel oil sorted data

Figure 4. Histogram of the water rate determinated by extraction with betacarotenes molecules using a heavy oil Clevenger extractor process for gas oil data (4.a) and for fuel oil data (4.b).

\subsubsection{Control Charts of This Water Rate Determination by Extraction with Betacarotenes Molecules Using a Heavy Oil Clevenger Extractor Process Used in Gas Oil and Fuel Oil}

Control charts show the variation in a measurement during the time period that the water rate determinated by extraction with betacarotenes molecules using a heavy oil Clevenger extractor process for gas oil and for fuel oil are observed. There are two types of control charts, first there is control limit Range R- chart [figure 5.a-figure 5.b] and secondly X-bar chart [figure 6.a - figure 6.b] [6,7]. We notice that the values of Range $\mathrm{R}$ which is the difference between the maximum data and the minimum data and $\mathrm{X}$-bar the medium of data are all in the neighboring of each middle values [Table 5-Table 6].

Table 5. $\bar{x}$ and $R$ values of water rate data extracted with betacarotene molecules in $800 \mathrm{ml}$ volume $V$ of gasoline using a Heavy oil Clevenger extractor process.

\begin{tabular}{lllllll}
\hline $\begin{array}{l}\text { SAMPLING } \\
\text { [Station }\end{array}$ ] & \multicolumn{6}{l}{$\begin{array}{l}\text { Water rate [ml] extracted with betacarotenes molecules } \\
\text { in } 800 \text { ml volume V of gasoline using a Heavy oil } \\
\text { Clevenger extractor process }\end{array}$} \\
\cline { 2 - 7 } & $\mathbf{V}$ & $\mathbf{V}$ & $\mathbf{V}$ & $\mathbf{V}$ & $\mathbf{R}$ & $\overline{\boldsymbol{x}}$ \\
\hline Station 1 & 0,150 & 0,140 & 0,155 & 0,145 & 0,015 & 0,147 \\
Station 2 & 0,145 & 0,135 & 0,150 & 0,155 & 0,020 & 0,146 \\
Station 3 & 0,140 & 0,150 & 0,145 & 0,150 & 0,010 & 0,146 \\
Station 4 & 0,160 & 0,160 & 0,150 & 0,140 & 0,020 & 0,152 \\
Station 5 & 0,155 & 0,145 & 0,140 & 0,150 & 0,015 & 0,147 \\
\hline
\end{tabular}

Table 6. $\bar{x}$ and $R$ values of water rate data extracted with betacarotene molecules in $200 \mathrm{ml}$ volume $V$ of gasoline using a Heavy oil Clevenger extractor process.

\begin{tabular}{|c|c|c|c|c|c|c|}
\hline \multirow[t]{2}{*}{$\begin{array}{l}\text { SAMPLING } \\
\left.\text { [Sample }_{\mathrm{i}}\right]\end{array}$} & \multicolumn{6}{|c|}{$\begin{array}{l}\text { Water rate }[\mathrm{ml}] \text { extracted with betacarotenes molecules } \\
\text { in } 200 \mathrm{ml} \text { volume } \mathrm{V} \text { of fuel oil using a Heavy oil } \\
\text { Clevenger extractor process }\end{array}$} \\
\hline & $\mathbf{V}$ & $\mathbf{V}$ & $\mathbf{V}$ & V & $\mathbf{R}$ & $\bar{x}$ \\
\hline Sample 1 & 0,5 & 0,6 & 0,4 & 0,5 & 0,20 & 0,500 \\
\hline Sample 2 & 0,3 & 0,4 & 0,6 & 0,5 & 0,30 & 0,450 \\
\hline Sample 3 & 0,4 & 0,6 & 0,5 & 0,4 & 0,20 & 0,475 \\
\hline Sample 4 & 0,5 & 0,4 & 0,5 & 0,6 & 0,20 & 0,475 \\
\hline Sample 5 & 0,4 & 0,5 & 0,6 & 0,4 & 0,20 & 0,475 \\
\hline
\end{tabular}

From these tables we deduce the Lower Control Limit (LCL) and the Upper Control Limit (UPL) for R and X-bar values [7].
For every sampling both the $\mathrm{R}$ and X-bar points are in the limits zone [figure $5 . \mathrm{a}$ - figure 5.b, figure $6 . \mathrm{a}$-figure 6.b]. It means that water rate extracted with betacarotenes molecules in $800 \mathrm{ml}$ volume of gas oil and in $200 \mathrm{ml}$ volume $\mathrm{V}$ of fuel oil using a Heavy oil Clevenger extractor process occurs all of the time with stability and consistent (99.7\%) [figure 5 - figure 6]. We notice that the fluctuations of the data in the gas oil R-chart [figure 5.a] and fuel oil X-chart [figure 6.b] are normally constituted and attributed to statistical variability. They confirm and show the capabilities of this process to be statistically in control [7]. Over wise, the fluctuations of the three latest data in the gas oil X-chart [figure 5.b] corresponds to a special sequence such as correctives actions will be necessary if and only if it sequence will continue. In this case, this correction is not necessary because the gas oil R-chart data's [figure 5.a] are normally constituted [7]. So, it is possible that the latest data of the gas oil R-chart is aberrant.

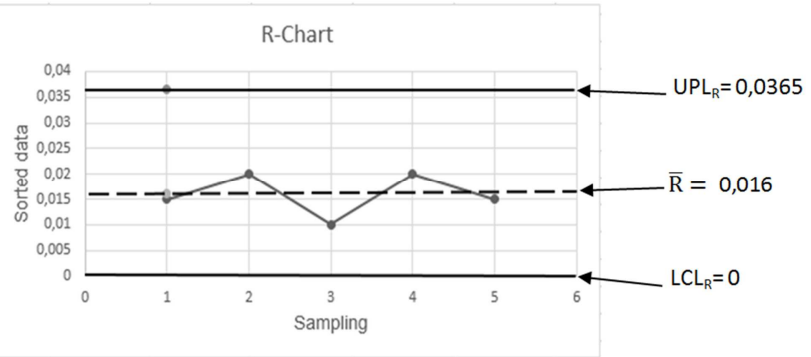

(5.a-Gas oil sorted data)

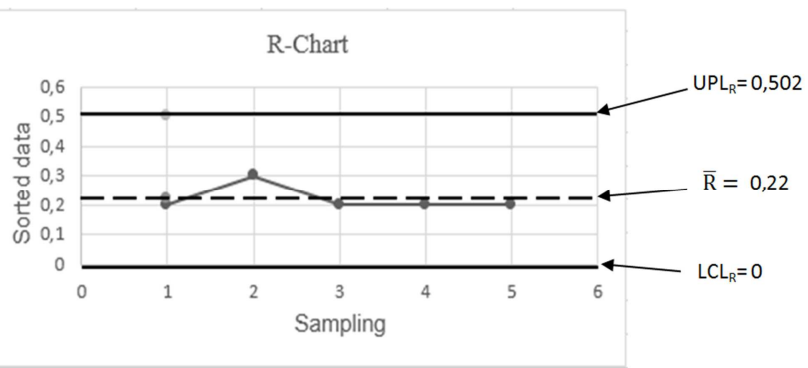

(5.b-Fuel oil sorted data)

Figure 5. Range R-Chart for the data of the water rate determinated by extraction with betacarotenes molecules using a heavy oil Clevenger extractor process for gas oil data (5.a) and for fuel oil data (5.b). 

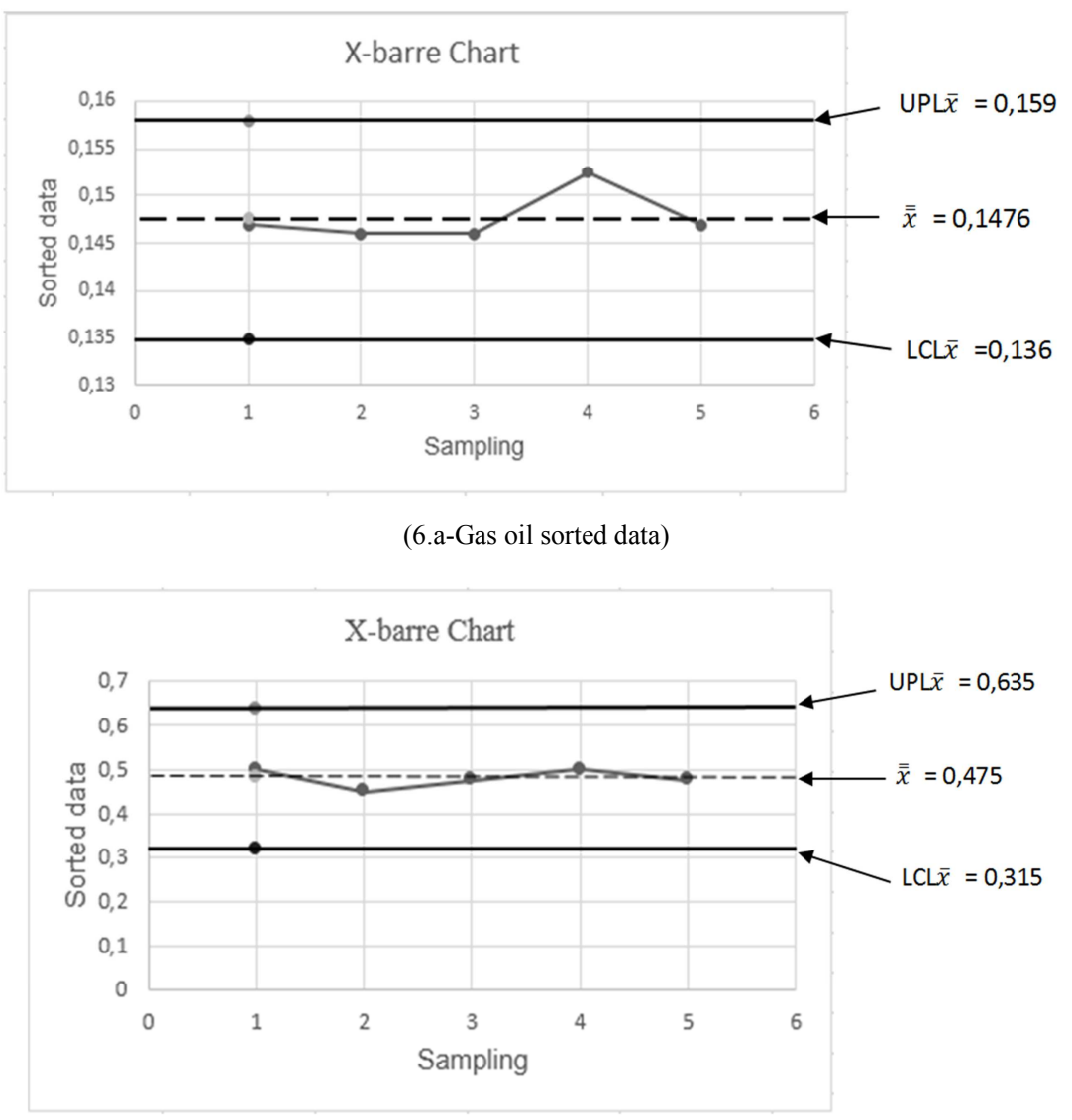

(6.b-Fuel oil sorted data)

Figure 6. X-bar Chart for the data of the water rate determinated by extraction with betacarotenes molecules using a heavy oil Clevenger extractor process for gas oil data (6.a) and for fuel oil data (6.b).

\subsection{Aptitude of This Water Rate Determination by Extraction with Betacarotenes Molecules Using a Heavy Oil Clevenger Extractor Process}

\subsubsection{Bibliography of Water Rate in Gas Oil and Fuel Oil}

Actual standards and procedures use benzene molecules like active reagents. We notice that the water rate accepted in gas oil and fuel oil change according to the country. For the gas oil, the water rate accepted data in $800 \mathrm{ml}$ is between $0.135 \mathrm{ml}$ to $0.4 \mathrm{ml}$ and for the fuel oil the water rate accepted data in $200 \mathrm{ml}$ is between $0.3 \mathrm{ml}$ to $1.26 \mathrm{ml}$ [Table 7-Table 8].

Table 7. Accepted water rate equivalent in $800 \mathrm{ml}$ of Gas oil using actual standards and procedures according to the country.

\begin{tabular}{lllll}
\hline GAS OIL (GO) & \multicolumn{1}{l}{} & & \\
\hline & $\begin{array}{l}\text { Standards and Procedures Used for } \\
\text { the Water Rate Determination }\end{array}$ & $\rho\left[\mathrm{Kg} / \mathrm{m}^{3}\right]$ & Water Rate Accepted & $\begin{array}{l}\text { Accepted Water Rate Equivalent } \\
\text { in } 800 \mathrm{ml} \text { of gasoil }\end{array}$ \\
& NF ISO 12937 & {$[820,845]$} & $\leq 200 \mathrm{mg} / \mathrm{Kg}$ & $\leq 0.135 \mathrm{ml}$ \\
Total Gazole Premier & ASTM D 95 & {$[820,845]$} & $\leq 0.05 \mathrm{ml} / 100 \mathrm{ml}$ & $\leq 0.4 \mathrm{ml}$ \\
Gas Oil Imported by Madagascar & A & &
\end{tabular}

Table 8. Accepted water rate equivalent in $200 \mathrm{ml}$ of fuel oil using actual standards and procedures according to the country.

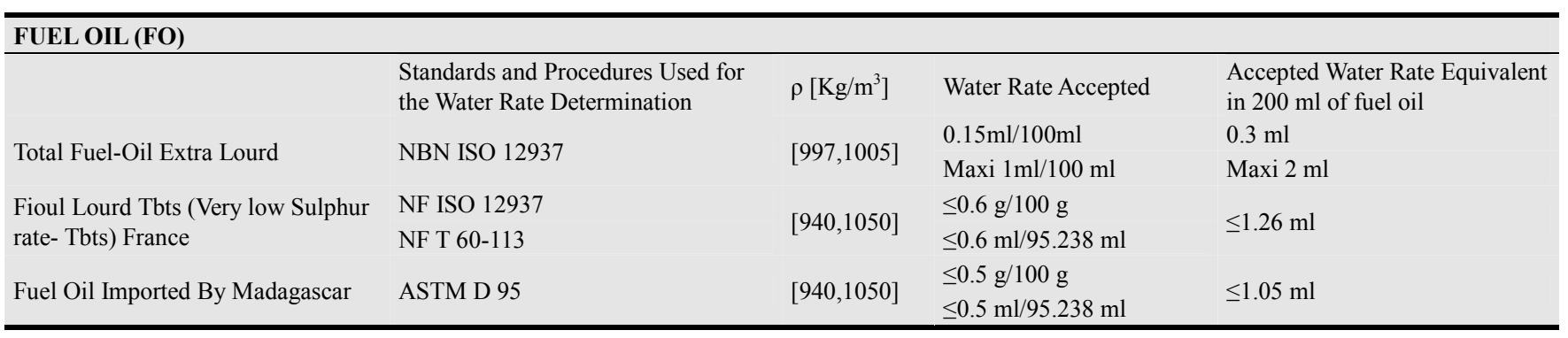


The aptitude of this water rate determination by extraction with betacarotenes molecules using a heavy oil Clevenger extractor process measures the degree of conformity of this one compared to the specifications for a given service. The specifications are often expressed in target, supplied with a tolerance. In this case, we have taken first the LCL and UPL values to express the specifications and at the second the Total service specification target [Table 7-Table 8] with heavy oil Clevenger extractor tolerance which is \pm 0.1 [ml] and standard deviation. One can quote two indicators to measure the aptitude of a process. Initially, there is the ratio of aptitude of the process $\mathrm{Cp}$, then there is the index of aptitude of the process Cpk [7]. A process is suited to the production when, in its distribution, the extreme values remain inside the tolerances specified for the product or the service and the difference between the high tolerance and the tolerance low, called width of tolerance, must be higher than a standard deviation of 6 .

\subsubsection{Aptitude Ratios Cp of This Water Rate Determination Process Used in Gas Oil and Fuel Oil}

$$
\mathrm{Cp}=\frac{\text { High tolerance }- \text { Low tolerance }}{6 \sigma}
$$

Such as $\delta$ the standard deviation of the normal distribution of this water rate determination process is equal to 0.0027 for the gas oil and 0.021 for fuel oil.

We present in the following tables the $\mathrm{Cp}$ results of this water rate determination in gas oil [Table 9] and fuel oil [Table 10] by extraction with betacarotenes molecules using a heavy oil Clevenger extractor process according to the two cases of specifications. It indicates that this water rate determination in gas oil process [Table 9] produce results with a quality six sigma if we consider the high tolerance of Total service specification target and the heavy oil Clevenger extractor tolerance with standard deviation. Over wise, we notice that if we considered only the tolerance given by the data exploitation (first specification with LCL - UPL with standard deviation) the quality is four sigma. That is to say statistically the water rate determination in gas oil with betacarotenes molecules using a heavy oil Clevenger extractor process will produce less than $0.0063 \%$ defects results. For fuel oil [Table $10]$, this water rate determination process produce results with a quality six sigma. That is to say, all the time this process produce not more than $0.0000002 \%$ defects results.

Table 9. Cp and quality values of water rate determination in gas oil by extraction with betacarotenes molecules using a heavy oil Clevenger extractor process according to the specifications.

\begin{tabular}{|c|c|c|c|c|}
\hline Specifications & High Tolerance & Low Tolerance & Cp & Quality \\
\hline $\begin{array}{l}\text { First Specification } \\
\text { (LCL - UPL of X-barre with standard deviation) }\end{array}$ & 0.159 & 0.136 & 1.42 & Four Sigma \\
\hline $\begin{array}{l}\text { Second Specification } \\
\text { (Gas oil Total service specification target [Table 7] with Heavy oil Clevenger extractor } \\
\text { tolerance and standard deviation) }\end{array}$ & 0.135 & 0.043 & 5.679 & Six Sigma \\
\hline
\end{tabular}

Table 10. Cp and quality values of water rate determination in fuel oil by extraction with betacarotenes molecules using a heavy oil Clevenger extractor process according to the specifications.

\begin{tabular}{|c|c|c|c|c|}
\hline Specifications & High Tolerance & Low Tolerance & $\mathbf{C p}$ & Quality \\
\hline $\begin{array}{l}\text { First Specification } \\
\text { (LCL- UPL of X-barre with standard deviation) }\end{array}$ & 0.635 & 0.315 & 2.54 & Six sigma \\
\hline $\begin{array}{l}\text { Second Specification } \\
\text { (Fuel oil Total service specification target [Table 8] with Heavy oil Clevenger extractor } \\
\text { tolerance and standard deviation) }\end{array}$ & 2 & 0.3 & 13.492 & Six sigma \\
\hline
\end{tabular}

\subsubsection{Aptitude Index Cpk of This Water Determination Process Used in Gas Oil and Fuel Oil}

$$
\mathrm{C}_{\mathrm{pk}}=\text { Minimum of }\left[\frac{\overline{\bar{x}} \text {-Low tolerance }}{3 \sigma}, \frac{\text { High tolerance }-\overline{\bar{x}}}{3 \sigma}\right]
$$

We present in the following tables the Cpk results of this water rate determination in gas oil [Table 11] and fuel oil [Table 12] by extraction with betacarotenes molecules using a heavy oil Clevenger extractor process according to the two cases of specifications. For all specifications other the second specification for gas oil, Cpk values are more than 1.0. They confirm the results quality of this water rate determination in gas oil and fuel oil by extraction with betacarotenes molecules using a heavy oil Clevenger extractor process. The negative value of gas oil Total service specification target $\mathrm{Cpk}$ is because of the medium value $(0.1476)$ is near to the high tolerance value $(0.135)$ [7]. It confirms the four quality sigma of this gas oil water rate determination process which consequently produce not more than $0.0063 \%$ defects results. We notice also that the $\mathrm{Cp}$ and $\mathrm{Cpk}$ values are sensibly equal both in the first specification for gas oil and fuel oil, it indicates that the middle values of the normal distribution data of water rate determinated in gas oil and fuel oil are the nearest of the nominal values [7] such as:

- The water rate in Malagasy imported gas oil determinated by extraction with betacarotenes molecules using a heavy oil Clevenger extractor process is 0.1476

- The water rate in Malagasy imported fuel oil determinated by extraction with betacarotenes molecules using a heavy oil Clevenger extractor process is 0.475 
Table 11. Cpk values of water rate determination in gas oil by extraction with betacarotenes molecules using a heavy oil Clevenger extractor process according to the specifications.

\begin{tabular}{|c|c|c|c|c|c|}
\hline Specifications & $\begin{array}{l}\text { High } \\
\text { tolerance }\end{array}$ & $\begin{array}{l}\text { Low } \\
\text { tolerance }\end{array}$ & $\frac{\overline{\bar{x}}-\text { Low tolerance }}{3 \sigma}$ & $\frac{\text { High tolerance }-\overline{\bar{x}}}{3 \sigma}$ & Cpk \\
\hline $\begin{array}{l}\text { First Specification } \\
\text { (LCL - UPL of X-barre) }\end{array}$ & 0.136 & 0.159 & 1.432 & 1.604 & 1.432 \\
\hline $\begin{array}{l}\text { Second Specification } \\
\text { (Gas oil Total service specification target [Table 7] with Heavy } \\
\text { oil Clevenger extractor tolerance and standard deviation) }\end{array}$ & 0.135 & 0.043 & 12.914 & -1.555 & -1.555 \\
\hline
\end{tabular}

Table 12. Cpk values of water rate determination in fuel oil by extraction with betacarotenes molecules using a heavy oil Clevenger extractor process according to the specifications.

\begin{tabular}{|c|c|c|c|c|c|}
\hline Specifications & $\begin{array}{l}\text { High } \\
\text { tolerance }\end{array}$ & $\begin{array}{l}\text { Low } \\
\text { tolerance }\end{array}$ & $\frac{\overline{\bar{x}}-\text { Low tolerance }}{3 \sigma}$ & $\frac{\text { Hightolerance }-\overline{\bar{x}}}{3 \sigma}$ & Cpk \\
\hline $\begin{array}{l}\text { First Specification } \\
\text { (LCL- UPL of X-barre) }\end{array}$ & 0.635 & 0.315 & 2.540 & 2.540 & 2.540 \\
\hline $\begin{array}{l}\text { Second Specification } \\
\text { (Fuel oil Total service specification target [Table 8] with Heavy } \\
\text { oil Clevenger extractor tolerance and standard deviation) }\end{array}$ & 2 & 0.3 & 2.777 & 24.06 & 2.777 \\
\hline
\end{tabular}

\section{Betacarotenes Recycling}

We have investigated the recycling of betacarotenes used during the water rate determination in gas oil and fuel oil by extraction using a heavy oil Clevenger extractor process. We notice that during the extraction of water in the hydrocarbons, the betacarotenes molecules are introduced in the gas oil and fuel oil then they are heated together. After at least thirty five minutes, all of the water molecules in the hydrocarbons are extracted and the process is stopped. We obtain a dark orange solution composed of betacarotenes molecules and hydrocarbons. To recycle the betacarotenes molecules, we use the process number one described in our first publication [8]. The first step is to introduce the acetic acid solvent in the dark orange solution. From this moment, the hydrogen bond link between the betacarotenes molecules and acetic acid molecules occurs progressively. We transvase the solution in a settle ampoule and let it rest for thirty minutes. Two phases are observed. Betacarotenes molecules with acetic acid are underneath and on top there were hydrocarbons because their density are less than the betacarotenes-acetic acid density. Then, we get back the betacarotenes-acetic acid solution and in the same time hydrocarbons are recycled. The second step is to neutralize this solution with distillated water: water neutralization. The $\mathrm{pH}$ of the solution increased and progressively betacarotenes molecules, which are insoluble in water, became on top up to gather. After thirty minutes, we obtain two phases and underneath there is acetic acid solution which are up to gather because of dimers hydrogen bond link. Finally, we get back the betacarotenes molecules using a settle ampoule [Figure 7]. To improve the betacarotenes extraction rate, we have repeated three times the first step. Finally, the betacarotenes recycled rate in hydrocarbons are $75 \%$ for gas oil and $60 \%$ for fuel oil.

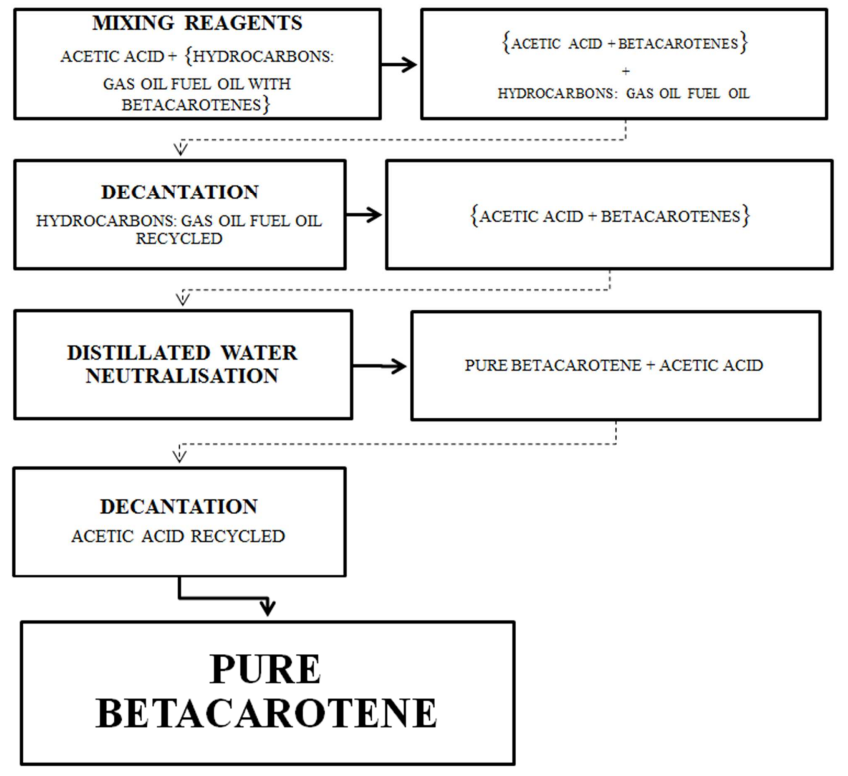

Figure 7. Flow-sheet of recycling betacarotenes and hydrocarbons gas oil and fuel oil process.

\section{Conclusion}

Hydrocarbons water rate determination process with betacarotenes molecules using a heavy oil Clevenger extractor is apt to give the right rate of water in hydrocarbons such as fuel oil and gas oil with quality six sigma in comparison to Total service specification target. Not only this process is environmentally responsible but also it is the most profitable process energetically and financially. Actually, we use only $10 \mathrm{ml}$ of betacarotene, an environmentally responsible reagent, in each analyze and its duration is less than one hour, approximatively thirty five minutes. We notice that after use, betacarotenes is recycled approximatively more than $60 \%$. 


\section{Acknowledgements}

Special Thanks to everyone who have supported and helped us to carry out this paper. As well, we express our sincere thanks to Director of E.S.P.A Polytechnic of the Antananarivo University and Chemical Engineering Laboratory staff. Special thanks to the company Savonnerie Tropical Madagascar for giving us unrefined palm oil through which we have extracted betacarotenes used during the experiences. We are sincerely grateful to everyone who has thinking of us during the realization of this paper.

\section{References}

[1] United Nations Environment Programme (UNEP) Agenda 21 www.unep.org.

[2] AFNOR www.afnor.org, NF ISO 12937, Editions 2016.

[3] ASTM International Standard Products www.astm.org ASTM D 95 .

[4] NBN bureau for standardization www.nbn.be.fr NBN ISO 12937.

[5] AFNOR www.afnor.org NF T 60-113, Editions 2016.

[6] (C) 2007 Statit Software, Inc., 1128 NE 2nd St, Ste 108, Corvallis, Oregon 97330 Introduction to statistical process control techniques.

[7] Larry Ritzmann, Lee Krajewski, Jacky Renart, Christopher,
Management des opérations Principes et applications, 2013, 2ème Edition, Eds Nouveaux Horizons.

[8] Andry Tahina Rabeharitsara, Phandry Nomena Ndjiva Rabearimihaja. New Processes to Extract Pure Betacarotenes Molecules Using Acetic Acid Solvent. American Journal of Applied Chemistry. Vol. 4, Issue 2, April 2016, pp. 64-70.

[9] Handbook of Chemistry \& Physics, $96^{\text {th }}$ Edition.

[10] Arunan, G. R. Desiraju, R. A. Klein, J. Sadlej, S. Scheiner, I. Alkorta, D. C. Clary, R. H., Crabtree, J. J. Dannenberg, P. Hobza, H. G. Kjaergaard, A. C. Legon, B. Mennucci, D. J. Nesbitt. Pure Appl. Chem. 83, 1619 (2011).

[11] Levey S, Jennings E R. The use of control charts in the clinical laboratories. Am J Clin Pathol 19502010591066.1066 .

[12] Henry R J, Segalove M. The running of standards in clinical chemistry and the use of the control chart. J Clin Pathol 19525305-311.311 [PMC free article] [PubMed]

[13] Westgard J O, Barry P L, Hunt M R. et al A multi-rule Shewhart chart for quality control in clinical chemistry. Clin Chem 198127493-501.501 [PubMed]

[14] Carey N C, Cembrowski G S, Garber C C. et al Performance characteristics of several rules for self-interpretation of proficiency testing data. Arch Pathol Lab Med 20051299971003.1003 [PubMed]

[15] Dr. Bill McNeese, Normal Probability Plots, June 2009, BPI Consulting, LLC. 